\title{
The Pedagogy of Pilgrimage on the Camino de Santiago Written into Performance
}

\author{
Sarah Peters
}

Flinders University, Adelaide, Australia

\begin{abstract}
Blister is a verbatim play that tells the story of Rosie, an Australian woman, who is walking the Camino de Santiago. The Camino is an $800 \mathrm{~km}$ pilgrimage across Northern Spain that begins in the French Pyrenees and traverses mountains, vineyard covered hills, mesetas (plateaus) and urban centres before concluding at Santiago de Compostela. 200,000 people from across the world walk the Camino every year, often carrying their minimal belongings in a backpack, staying in dormitory-style accommodation with fellow pilgrims in local albergues, and walking between 20$35 \mathrm{kms}$ most days. This short essay describes how walking methods merged with the situated, relational and material verbatim theatre practice of community immersion in order to experience and represent the public pedagogy of the Camino in performance. Informed by a feminist position and engaging with theatrical conventions inspired by queer theory, excerpts of Blister are incorporated across the essay to demonstrate how theatre as a live and embodied medium provides a multi-dimensional platform to depict the motion, emotion and learning experienced by pilgrims walking the Camino.
\end{abstract}

\section{Keywords}

Camino; verbatim theatre; dramaturgy; pilgrimage 
MOTHER CAMINO: Every day you come.

With your feet and your fears and your tongues.

I can feel it - your heart. Beating the familiar ballad of anticipation.

A river of walkers, breathing in, breathing out.

I see you.

The above excerpt is from Blister, a verbatim play about walking the Camino de Santiago: an $800 \mathrm{~km}$ pilgrimage across Northern Spain. In 2016, I set out to interview fellow pilgrims walking the Camino de Santiago, and write these stories into performance. In this short essay, I will introduce verbatim theatre, discuss how audiences learn from performance in an embodied way, and suggest that this form is a propitious medium for representing the lived experience of public pedagogy. I offer Blister as a unique case study for exploring the intersections between walking, the experience of public pedagogy on pilgrimage, the verbatim theatre practice of community immersion, walking methodologies to engage in storytelling, and queer-feminist frameworks for representing experiences in theatre using dramatic languages. Blister models a pedagogy of vulnerability by depicting characters in the act of navigating their sense of self, and their relationship with place, memory, and other bodies in response to their experience on the Camino. The play also embraces a queering of the theatrical representation of walking by "defamiliarizing established assumptions that walking is a convivial practice and that all bodies move through space equally" (Truman \& Springgay, 2019, p. 2-3).

Verbatim theatre involves interviewing a community of participants about an experience or event, recording these conversations, and using the resulting stories in the creative development of performance. The interviews or immersion within a community (one of the defining features of a verbatim process) can also serve to inform a playwright or theatre maker's direction for a work (Wake, 2018). One of the qualities that makes verbatim theatre such an engaging and transformational form of storytelling for audiences is that it is an embodied experience about embodied experience. The live performance of experience has advantage over textual representations because it "sustains connections to bodies, emotions and the full range of sensory experience" (Gray et al, 2000, p. 138). The liveness of theatre - the copresence of bodies in space - means that those stories about sensory, lived, and embodied experiences are shared in a sensory, lived, and embodied way. Welton (2012) advocates that audiences "get a feel for" (make sense of) performance through an active exchange "between the physical and the psychological, the personal and the worldly" (p. 12). This suggests that to understand theatre means feeling it. The tangible nature of theatre provides an opportunity to aesthetically depict the activity of walking, and as part of the broader categorisation of "theatre of the real," verbatim theatre "stages memory and history to create new aesthetic versions of human experience" (Martin, 2013, p. 17). Just as Tolia-Kelly (2008) describes art practices such as painting as "giv[ing] tangible expression and articulation to more abstract experiences of motion and emotion" (as cited in Myers, 2011, p. 184), the dramatic languages of theatre such as movement, space, sound and light move beyond the limits of language in their ability to depict physicality, materiality and feeling. 
My community immersion practice includes a process of actively engaging with the community whose stories will be shared; this process emphasises building awareness of and participation in the playwriting project, and committing to support the community of storytellers. This triangulated approach is an ethical practice that enables the playwright to write more authentically about/with a community (Paget, 2010), while also seeking contrasting and challenging perspectives. In the Blister project, community immersion meant walking the Camino, which became both the object of study and a situated, relational and material method of practice. Training for the Camino, researching packing lists and learning conversational Spanish were also integral to the preparation for this project. In my previous verbatim theatre practice, I have organised formal recorded interviews; however, on the Camino I engaged with Myers' (2011) "conversive wayfinding" (p. 187) and Anderson's (2004) "talking whilst walking" methods (p. 260) to generate material for performance. Myers' (2011) conversive wayfinding involves "a spatial practice of walking that activates encounters within and with particular contexts through ambulant, kinaesthetic and communicative movement and interaction" (p. 187). These interactions are not limited to human-human verbal exchanges, but rather "an embodied multi-sensorial and multi-directional sense of communication and motion is involved that includes various dimensions of connection with the materiality of the world the walkers move within" (Myers, 2011, p.188). An aspect of this relationship with the material world is represented in the excerpt below. The protagonist Rosie shares;

ROSIE: It is hard you know. You're following yellow arrows across a country, which is mad really. You set off with your backpack in the morning, keeping an eye out for these little yellow arrows painted onto trees, gutters, the corners of buildings - and this is what you follow to get from place to place. You're crossing fields and mountains with complete faith in small strips of yellow paint.

Anderson's (2004) talking whilst walking method is a "collage of collaboration: an unstructured dialogue where all actors participate in a conversational, geographical and informational pathway creation [...] atmospheres, emotions, reflections and beliefs can be accessed, as well as intellects, rationales and ideologies" (p. 260). The medium of theatre allows these knowledges to be depicted in diverse ways, through soundscapes, dialogue and choreography, which reflect the emotive, reflective and conversational nature of the story's original context on the Camino. Both conversive wayfinding and talking whilst walking embrace context and geography as integral components to learning. In relation to the practice of community immersion, walkers are prompted not only by questions, "but also by the interconnections between the individuals and the place itself" (Anderson, 2004, p. 258). The materiality of the path is essential to the walking interview. As we shared our pace and experience as pilgrims, we shared ourselves, sometimes talking about the experience of the Camino, but also regularly about how the Camino and our spatial relationships in this place "are interrelated with original home memories and home identity making” (Myers, 2011, p. 185). This is represented in the following excerpt:

$\begin{array}{ll}\text { JUDY: } & \text { "Locally known as 'Sa Venda” } \\ \text { ROSIE: } & \text { For Sale } \\ \text { JUDY: } & \text { Sorry? } \\ \text { ROSIE: } & \text { The nickname of the town - For Sale }\end{array}$


JUDY: Jesus. Where is everybody?

KATE: Gone.

ROSIE: $\quad$ Everything's so new and clean.

JUDY: And empty.

Anyone feel like stopping?

KATE: I feel like at any minute a bunch of zombies are going to jump out and attack us.

JUDY: I'll take that as a no then.

Judy and Kate exit.

ROSIE: It was the eeriest place. There was no-one, not a single soul in the whole town. Tennis courts, perfectly manicured lawns, newly built estates. Not like the ghost towns back home in Queensland, forgotten after the mining boom. More like an empty movie set. Waiting. Still.

Through this evocation of home, Rosie is positioned as someone with a history beyond her current context on the Camino, and that history informs the way she perceives her journey. It also reminds the audience that she is a visitor on the Camino. In Blister this is one of the first moments that Rosie mentions home, and from here the theme continues to echo throughout the play. Rosie's relationship with the context and geography of the Camino is both familiar and strange, and in wrestling with this dichotomy she learns something about herself and the audience witnesses that learning.

Learning and discovery are key themes in the play, and in this sense, Blister represents characters navigating the pedagogy of pilgrimage on the Camino. Hickey (2010) describes the street as a pedagogue, a place of "both total involvement and immediate disconnection" as travellers move through the street, and a "place of vulnerabilities where we simultaneously aren't at home or 'there"' (p. 162). Blister captures this vulnerable state of learning and 'in between-ness' experienced by pilgrims who are part way through their journey, and represents these characters sharing this state of vulnerability with Rosie, and by extension, the audience:

EMILIA: (To audience) Do you want children? I wasn't sure either until I was so sure it hurt. My partner and I tried for more than 20 years. Trying, applied to adopt, trying - always unsuccessful.

I first walked the Camino 3 years ago, giving myself this space to come to terms with the fact that I might not get to be a mother. 34 days to put down an idea I'd been holding onto. What would my legacy be?

I have a friend in India, she is like family. She works everyday with homeless children and she said to me recently 'Emilia, there is more than one way to be a mother'. 
Should I move to be with her in India, and open an orphanage there? Share love and care in this way?

This is why I'm walking the Camino again - and hopefully, when I reach Santiago de Compostela, I'll know.

The play is modelling a pedagogy of vulnerability, the act of opening yourself up, contextualising who you are within "societal constructs and systems," learning with others and being able to "admit you do not know, and be human" (Brantmeier, 2013, p. 96). In the excerpt above Emilia is laying bare the knowledge she seeks to learn from the Camino, and through performance this vulnerability is modelled and shared with the audience.

Learning to navigate via the yellow arrows or shell symbols dotted periodically along the Camino is an exercise in trust. Through a combination of sound effects, direct address, and the targeted use of silence, the following excerpt represents how the geography and materiality of the Camino is pedagogical:

ROSIE: Is it called getting lost when you're on a pilgrimage? Or is it just that you're "making your own unique way along the road"?

N1: $\quad$ You can't silver lining this one Rosie.

N2: $\quad$ You got lost. Pure and simple.

ROSIE: Day three and I'd set off early and incredibly confident. I knew to cross the bridge and turn left. Cross the bridge. Turn Left. Did I mention it's still quite dark? The lights of town glittering a constellation over the river. A gentle tinkling of bells from the paddock as the cows move slowly from one mouthful to the next. Silence. And I think "This is it. The idyllic pilgrim makes their way along a darkened path, appreciating the beauty all around them."

Cow bells. Mud. Manure. A distinct lack of yellow arrows.

A weird anxiousness begins to bloom. Heart rate kicks up a notch.

What if I'm...maybe...if this isn't the path then... where am I?

How long do you walk down the wrong path?

I'll give myself 5 minutes. If I haven't seen an arrow, or another pilgrim, I'll turn back.

Yes. Good plan.

Two minutes.

Three cows and an extra inch of mud.

Four minutes.

Lights of town fading.

Cow bells are heard in the distance. 
Four and a half minutes.

I'll go back. Yes. Good plan.

The dormitory-style accommodation, occasional communal bathroom facilities, and prescribed pilgrims' menus at many cafes and restaurants are "public discourses [that] form and shape us in ways that we do not acknowledge as pedagogical" (Huckaby, 2010, p. 72). Blister seeks to acknowledge this and make representations of how the public pedagogy of the Camino teaches pilgrims personal lessons.

The dramaturgy of Blister is informed by queer theory and a feminist frame that positions gender as both a social construction and a performed role advocating that sexuality can be "open to varied and shifting practices and identities" (Fortier, 2016, p. 98). There are three actors in the cast of Blister; Rosie is played by one actor throughout the entire performance, however the other two actors embody over 30 different characters ranging in age, gender, sexuality and nationality. This convention makes the shifting and performative nature of identity a tangible and explicit feature of the play, following queer theory's interrogation of "the historical and cultural positioning of the unified 'self" (Watson, 2005, p. 68) and presenting gender in particular as "only ever parody" (Lloyd, 1999, p. 198). For example, one actor performs the role of a 23-year-old English girl, and then a 70 year old Danish man within a matter of minutes. While the role of Rosie is performed by one actor, her identity is not stable across the performance but rather reflects Watson's (2005) definition of being queer; she is "in flux, contesting boundaries, eliding definition and exhibiting the constructedness of categorisation" (Watson, 2005, p. 74). This state of flux is prompted by her engagement with the pedagogy of the Camino and her ensuing learning about and wrestling with her sense of self. This is evident in the moment where Rosie walks up to Cruz de Heirro, the Iron Cross, where traditionally pilgrims leave a stone that they have been carrying with them. This moment in the play is delivered as a direct address description of a past event, with the actor reliving the emotion of the moment as if in present tense:

ROSIE: So I went up on my own.

Earlier that day I'd been thinking about a line from a movie; "I wish I knew how to quit you." And the fact that I haven't felt a love like that physically hit me in the chest like a roadtrain.

It happened again that afternoon. I was walking up the mountain, humming away. I looked up and saw it, the cross.

And suddenly I just, couldn't breathe.

And I asked myself, well, ok then, what if you have to face that?

What if you have to face the idea that maybe you won't can't? - be loved like that.

That it's not who you are.

Can I make that ok?

Pause. Grace enters.

GRACE: Rosie?

ROSIE: Grace. How are you? Sorry. 
GRACE: Don't, its ok. Crying is like breathing remember.

In an interview with playwright Jean Tong, director Bridget Balodis describes queer dramaturgy as seeking to disrupt patriarchal ideas of cohesion, completeness and coherency (Tong, 2018), embracing the state of not knowing advocated within a pedagogy of vulnerability. While there are elements of patriarchal dramaturgy in Blister-we follow Rosie on a relatively linear journey as she traverses the complete $800 \mathrm{kms}$ of the Camino-this is juxtaposed with a queering of traditional conventions as the audience are invited to nestle into lengthy moments of sharing and vulnerability. Audiences are frequently positioned to invest in characters that don't reappear in the story and are constantly witnessing characters in a state of "in between-ness and not knowing, tangibly embodying queer theory's deconstruction of normative notions of stable identity" (Nicolazzo, 2015, p. 22). In addition, the representation of Rosie's female body as strong and physically capable contradicts patriarchal constructions which "often reduce women to stereotypes [...] and fetishized body parts (breasts, vagina, face)" (Fortier, 2016, p. 87). Rosie, whose body has been represented as imperfect and flawed, praises her feet and lungs that have traversed the landscape of a country, and her self-acknowledgement at the play's conclusion is a radical statement about the human body's capacity for movement:

ROSIE: I have never been so proud of my body in my entire life. This body, these lungs, these thighs, these feet - they carried me across the entire breadth of a country. I've never loved myself more than I did in this moment.

In this verbatim theatre project, conversive wayfinding and talking while walking methods are integral to the practice of community immersion; these methods transformed the nature of the stories shared with me on the Camino and the way I have written them into performance. The physicality, motion and momentum of walking lead to dynamic, multi-sensorial and multi-directional stories being shared. The sheer duration of the walk-34 days to complete the $800 \mathrm{~km}$ - meant the relationships with the materiality of the Camino and my fellow pilgrims were layered, patterned, and had an iterative rhythm. Blister enables audiences to feelingly witness and experience the pedagogical impact of walking the Camino de Santiago, and points towards the propitious porosity between walking methodologies, verbatim theatre, and the representation of the lived experience of public pedagogy in performance.

\section{References}

Anderson, J. (2004). Talking whilst walking: A geographical archaeology of knowledge. Area 36(2), 254-261.

Tong, J. (2018). The dramaturgy of queer. Witness. Retreived June 2019, from https://witnessperformance.com/thedramaturgy-of-queer/

Brantmeier, E. (2013). Pedagogy of vulnerability: Definitions, assumptions, and applications. In J. Lin., R. Oxford. \& E. J. Brantmeier (Eds.), Re-Envisioning higher education: Embodied pathways to wisdom and transformation (pp. 95-106). Charlotte, MC: Information Age Publishing.

Fortier, M. (2016). Theory/theatre: An introduction. New York, NY: Routledge. 
Gray, R., Sinding, C., Ivonoffski, A., Fitch, M., Hampson, A. \& Greenberg, M. (2000). The use of research based theatre in a project related to metastatic breast cancer. Health Expectations 3(2), 137-144.

Hickey, A. (2010). When the street becomes a pedagogue. In J. Sandlin, B. Schultz, \& J. Burdick (Eds.), Handbook of public pedagogy (pp. 161-170). New York, NY: Routledge.

Huckaby, M. F. (2010). Public pedagogies, everyday politics on and of the body. In J. Sandlin, B. Schultz, \& J. Burdick (Eds.), Handbook of public pedagogy (pp. 71-81). New York, NY: Routledge.

Lloyd, M. (1999). Performativity, parody, politics. Theory, Culture \& Society 16(2), 195-213.

Martin, C. (2013). Theatre of the real. London, UK: Palgrave Macmillan.

Myers, M. (2011). Walking again lively: Towards an ambulant and conversive methodology of performance and research. Mobilities, 6(2), 183-201. https://doi.org/10.1080/17450101.2011.552775

Nicolazzo, Z. (2015). "I'm man enough; are you?": The queer (im)possibilities of walk a mile in her shoes. Journal of Critical Scholarship on Higher Education and Student Affairs 2(1), 18-30. Retrieved from https://ecommons.luc.edu/jcshesa/vol2/iss1/2/

Paget, D. (2010). Acts of commitment: Activist arts, the rehearsed reading and documentary theatre. New Theatre Quarterly, 26(2),173-193.

Peters, S. (2019). Blister. Unpublished manuscript.

Truman, S., \& Springgay, S. (2019). Queer Walking Tours and the affective contours of place. Cultural geographies in practice $00(0)$, Advanced online publication. https://doi.org/10.1177\%2F1474474019842888

Wake, C. (2018). Postcard From the Edge: Tom Holloway's Beyond the Neck and The Limits of Verbatim. Australasian Drama Studies, 72, 99-125.

Watson, K. (2005). Queer Theory. Group Analysis 38 (1), 67-81. https://doi.org/10.1177\%2F0533316405049369

Welton, M. (2012). Feeling theatre. Hampshire: Palgrave Macmillan.

Sarah Peters is a theatre artist and practice-led researcher whose verbatim plays engage with communities to tell the shared stories of experience. Her research traverses articulating the creative process of verbatim and devised works, investigating the impact of performance and engaging with alternative research methodologies for theatrically representing lived experience. 